\title{
Preguntas, indeterminaciones y conjeturas
}

\author{
Morgana Carranco \\ "El conocimiento nos hace responsables" \\ Ernesto "Che" Guevara
}

"Sucedía así que él crecía y yo no sabía lo propuesto, porque el pelo crecía aprisa y yo aprendía despacio, y con efecto le cortaba en pena de la rudeza: que no me parecía razón que estuviese vestida de cabellos cabeza que estaba tan desnuda de noticias, que era más apetecible adorno"

Sor Juana Inés de la Cruz

E camino del conocimiento no es lineal y, además del obvio esfuerzo que conlleva, está poblado de tropiezos, hipótesis equivocadas y coincidencias. El conocimiento, en todos sus ámbitos, es algo que perseguimos y perseguimos, pero que no es fijo. Por ello, este número de la Revista Digital Universitaria sintetiza las diferentes formas de explorar el conocimiento, su empleo e implicaciones para la sociedad.

En el camino del saber, aprendemos hoy algo que puede dejar de ser válido mañana. Sin embargo, el pasado y los orígenes suelen ser valiosos. En este sentido, como ejemplo de la importancia de los lugares de procedencia y del ayer, está el primer artículo del presente número de la Revista Digital Universitaria. En "Los últimos serán los primeros: la importancia de los hablantes de herencia", conocemos sobre los hablantes de herencia, cuya primera lengua es empleada en casa y que se maneja hasta cierto grado, pues está restringida por el contexto social dominante de su segunda lengua, de la que obtienen más estímulos, por lo que ésta prevalece. Esto se da, por ejemplo, en México en las lenguas originarias con relación al contexto dominante del español y, en Estados Unidos, en hijos de inmigrantes hispanohablantes con el inglés. Aquí se resalta la importancia de recuperar esas lenguas de herencia, de revitalizarlas y resignificarlas, puesto que nos dicen mucho de nuestra cultura, historia, origen y valores, y

Dol: http://doi.org/10.22201/cuaieed.16076079e.2021.22.4.0 
contribuyen a construir nuestra identidad.

Asimismo, en la búsqueda de conocimiento hay algo muy bello: siempre hay más que explorar. Basta recordar que no estamos solos en la Tierra, que nos acompañan muchísimas especies, algunas más cercanas que otras. Por ello, en la presente emisión de la rdu, examinamos nuestro mundo desde varios frentes. Primero, en "Flautistas, bagels y tortillas: la vida secreta de ratas y ratones", conocemos más acerca de los ratones y ratas, los mitos relacionados con ellos y sus verdaderos roles en nuestra vida diaria, así como en los ecosistemas.

Segundo, en "El enemigo de mi enemigo es... Un virus que ataca a las bacterias: los bacteriófagos", profundizamos sobre estos virus que atacan a las bacterias y de los cuales se aborda su biología, su importancia en el desarrollo de la ciencia, así como su contribución a la salud y su potencial como vehículos de transporte de moléculas, diagnosis y generación de vacunas.

Tercero, en "Bacterias del maíz como aliadas en la producción agroecológica de alimentos", conocemos que el biocontro/ permite utilizar componentes biológicos (insectos, hongos y bacterias) para controlar el crecimiento de otros seres que dañan los cultivos. De este modo, exploramos los detalles de esta técnica mediante un ejemplo, en el que se usa la bacteria de la rizósfera del maíz Bacillus cereus B25 para disminuir una enfermedad en el maíz causada por un hongo infeccioso.

Por último, en relación con la diversidad en el planeta en general, y en especial en la región del Pacífico mexicano, contamos con dos artículos "Las extraordinarias formas de vida de los dinoflagelados del Pacífico mexicano" y "Medusozoos: tesoro oculto del Pacífico mexicano". En el primero, los autores nos cuentan sobre los dinoflagelados marinos, el segundo grupo más abundante en el fitoplancton. Además, ahondan en sus funciones como producción de oxígeno y otros compuestos que pueden ser útiles para la sociedad. En el segundo texto, el tema son los meduzoos, animales de los cuales hemos oído por la existencia de especies como las medusas, pólipos y sifonóforos, que tienen gran importancia en lo ecológico, económico y social. Igualmente, se comparte más sobre su diversidad, distribución y la manera en que algunos científicos los estudian.

Sin duda, con el crecimiento de la ciencia, los humanos también hemos sido capaces de aplicarla, para tener una vida más sencilla. No obstante, hay desarrollos que en el momento de su creación pudieron parecer adecuados, pero que con el paso del tiempo representan un gran problema. Tal es el caso en "Una inundación global de pláticos". Corresponde, entonces, como seres racionales y responsables, encontrar una solución a esta cuestión que nosotros mismos hemos provocado, para evitar que siga afectando a nuestra Tierra y que, incluso, amenace nuestra existencia.

Sin embargo, no hay que permitir que los errores del pasado limiten nuestra búsqueda de conocimientos y su aplicación, porque también hay oportunidad de llevar a cabo cambios positivos. En este sentido, en "La termoelectricidad: convirtiendo 
el calor en electricidad", los autores analizan los mecanismos para la generación de electricidad — tan básica para nuestra forma de vida actual_, mediante el aprovechamiento del calor liberado por un proceso donde se realice un trabajo. Además de la alta disponibilidad de este tipo de energía, su uso nos permitiría reducir el impacto en el medio ambiente debido al uso de combustibles fósiles para la creación de electricidad.

En el ámbito social, vale la pena resaltar que, a pesar de todo el conocimiento que como humanidad poseemos, como sociedad todavía vivimos rodeados de prejuicios, discriminación y estigmas, y, lo peor, algunos se siguen perpetuando. Basta mencionar la discriminación racial o por preferencias sexuales, la violencia de género y los feminicidios. En este orden de ideas, incluso aunque se sabe que el aborto, la lactancia y la educación sexual son seguros, benéficos y eficaces, todavía nos desenvolvemos en una sociedad que los estigmatiza.

Por ello, en "Estigma hacia el aborto y sus consecuencias: acciones para reducirlo", las autoras tratan los diferentes ámbitos en los que lamentablemente existe una satanización hacia el aborto, lo cual, además, refleja la misoginia, el machismo y la oposición de un sector de la sociedad a dejar que las mujeres elijamos, y no hablo sólo de las decisiones sobre nuestro cuerpo. En este texto se exploran los niveles en los que se sigue presentando este discurso de odio hacia el aborto: lo mismo en los medios de comunicación y la opinión pública, que en lo legal, institucional, comunitario y hasta individual.

Asimismo, el artículo "Lactancia materna: rompiendo las barreras", se ahonda en las ventajas de la lactancia, tanto para el bebé como para la madre. Y, con fundamentos científicos sólidos, se le promueve, ya que, con muy pocas excepciones, es conveniente para ambas partes, a corto y largo plazo. Por mencionar algunos, disminuye el riesgo materno de cáncer de mama, de sangrado posterior al parto y mejora el vínculo emocional entre la madre y el hijo. En el caso del bebé, le ayuda en su desarrollo emocional y social, al tiempo que promueve el crecimiento de bacterias benéficas del tracto digestivo y de la piel.

En el mismo sentido, en "La educación sexual escolar... ¿Funciona?", las autoras comparan la impartición de la educación sexual en México y en otros países, y cómo la manera en la que se aborda en nuestro país se traduce en prácticas de riesgo, búsqueda de fuentes de información inadecuadas y la perpetuación de roles estereotipados de género y violencia contra la mujer.

Dichos textos nos recuerdan que es importante conocer y llevar a cabo acciones para reducir el estigma hacia el aborto, la lactancia y la educación sexual, ya que, aunque pareciera que sabemos más y estamos informados y abiertos al respecto, en nuestro contexto permanecen discursos obsoletos, infundados y discriminatorios que, como entes racionales y sociales, debemos erradicar, con la esperanza de una sociedad más incluyente, respetuosa y armónica.

Aún más, a pesar de todo nuestro conocimiento y tecnología, si hay algo que 
esta pandemia nos ha recordado, es que estamos inmersos en un mundo que se transforma y al que cambiamos a través de nuestras acciones; que dependemos del medio ambiente, de sus eventos estocásticos, como el surgimiento de nuevos virus. Es por ello que la capacidad de resiliencia que presentemos, la habilidad de adaptarnos ante nuevas condiciones, es clave.

De esta manera, en el texto "IIC: facilitadoras de la continuidad de actividades en la contingencia de covid-19" se explora y analiza el uso de las Tecnologías de Información y Comunicación (TIC) en un centro de investigación. Este caso particular es representativo de lo que hemos vivido durante el año anterior, y que probablemente tengamos que integrar a nuestro nuevo paradigma educativo. En el mismo sentido, en este número, incluímos el ahead of print de "Los retos educativos durante la pandemia de covID-19: segunda encuesta a profesoras y profesores de la UNAM", con la esperanza de que sea útil a los docentes universitarios de las distintas entidades y niveles, para reflexionar sobre las problemáticas, necesidades de formación, herramientas digitales y prácticas de enseñanza que comparten y pueden mejorarse.

Como ya lo mencioné, el conocimiento es algo que buscamos incesantemente, por lo que se puede percibir como lejano e inasible. Pero hay que recordar que se soporta y está construido por muchas personas. Esto lo ha puesto en evidencia la pandemia que seguimos enfrentando. Así, el desarrollo tan veloz de vacunas no es sólo producto de la gran inversión monetaria en el tema, del trabajo a marchas forzadas de los científicos, o de la generosidad de los ciudadanos que aceptaron contribuir para investigar la efectividad de las vacunas en ensayos clínicos. Es también resultado de los descubrimientos y técnicas que se fueron desarrollando a través del tiempo, de los conocimientos previos y de su difusión y entendimiento. Por ello, todos deberíamos ser parte de la comunicación de los saberes, lo que es uno de los objetivos de esta Revista.

El saber no es ese ente abstracto, alejado de lo cotidiano. El saber está más cerca de lo que imaginamos y crece cuando lo comunicamos, cuando lo hacemos llegar a otros, que, con una perspectiva diferente, pueden aportar a él y a todos. En este sentido, como lo expresa nuestra querida editora Rosa María del Ángel Martínez en "Dejando una huella durante el servicio social", la sección Caleidoscopio está dedicada a esos estudiantes que han contribuido con su servicio social a la misma existencia de esta Revista, a su papel en la difusión y comunicación social del conocimiento: de la ciencia, las humanidades y las artes. Sin ellos, no me queda ninguna duda, habría menos saberes al alcance de nuestra comunidad. Gracias por mejorar los artículos, por compartir su entusiasmo y energía con nosotras, y por enseñarnos tanto.

De igual manera, alcanzar el conocimiento depende mucho de que tengamos una predisposición y actitud para ello, y me refiero no sólo a las circunstancias adecuadas en lo social, económico y emocional. Hablo de que la búsqueda de nuevo conocimiento nos atraiga. Que veamos los saberes no como estáticos e inalcanzables, sino como una cuestión que provoca nuestra curiosidad y a la que podemos contribuir. Para ello, no hay mejor momento que la infancia. Entonces, una de las maneras de propiciar la 
búsqueda de conocimiento en los individuos se presenta en "Educación integral en la infancia: un aula innovadora, exitosa y feliz", donde, a través de la descripción de esta estrategia, se busca el desarrollo de las capacidades cognitivas, comunicativas, afectivas, sociales y creativas de los estudiantes, con un enfoque holístico.

Sin duda el conocimiento nos brinda certezas, pero nos regala, en mayor medida, preguntas, indeterminaciones y conjeturas. Son éstas, también, la forma en la que vivimos la vida, decidiendo lo que consideramos mejor con la información que poseemos. Son las preguntas, indeterminaciones y conjeturas las que nos mueven en esta búsqueda del saber, las que nos hacen cuestionar lo que conocemos y el rumbo que llevamos. Sin ellas no habría cambios de paradigmas, ni la cantidad y diversidad de los conocimientos y sus aplicaciones. Asimismo, sin las preguntas, indeterminaciones y conjeturas no podríamos cuestionarnos si estamos haciendo lo mejor que podemos como seres humanos, si lo que aprendemos es integrado para alcanzar una mejor sociedad.

La búsqueda del conocimiento es siempre abierta, mejorable, transformable. Y es algo a lo que todos podemos - y deberíamos - contribuir, ya sea ejerciendo nuestra profesión, fomentando los cambios de paradigmas sociales que se traduzcan en la construcción de comunidades más incluyentes y tolerantes, y cuestionándonos aquellos prejuicios que a veces, sin saberlo ni quererlo, también cargamos. Porque al igual que el conocimiento, somos seres siempre cambiantes y perfectibles.

\section{Morgana Carranco}

morgana.carranco@gmail.com orcid.org/0000-0002-2520-2560

Estudió la Licenciatura en Ciencias Genómicas, la Licenciatura en Lengua y Literaturas Hispánicas y la Maestría en Letras (Letras Mexicanas) en la Universidad Nacional Autónoma de México (UNAM). En 2017 fue seleccionada para participar en la Beca Juan Grijalbo, Seminario de Introducción al Mundo del Libro y la Revista, organizada por la CANIEM. Actualmente es editora técnica y correctora de estilo en la Revista Digital Universitaria, publicación de la UNAM para la comunicación social de las ciencias, las humanidades y las artes. Sus líneas de investigación son la figura de la bruja, la literatura fantástica y la comunicación social del conocimiento. Forma parte del Seminario de Literatura Fantástica Hispanoamericana de la UnAm.

\section{Cómo citar este ARtículo}

* Carranco,Morgana.(2021, julio-agosto).Preguntas, indeterminacionesy conjeturas. Revista Digital Universitaria (RDU), 22(4). http://doi.org/10.22201/cuaieed.16076079e.2021.22.4.0 